\title{
The relationship between pharmacy licensing policies on clinical training (CT) and success rates for international pharmacists (IPs) within Canada, United Kingdom, and the United States: A comparative policy analysis
}

\author{
Amad Al-Azzawi iD \\ The Ontario Institute for Studies in Education, Toronto University, Canada
}

\section{Keywords}

Comparative policy analysis

International pharmacist

Pharmacy education

\section{Correspondence}

Amad Al-Azzawi

Department of Leadership

Higher Education and Adult Education

Ontario Institute for Studies in Education

Toronto University

Canada

amad.alazzawi@mail.utoronto.ca

\begin{abstract}
Introduction: In October 2018, the Pharmacy Examining Board of Canada released a report showing that only $41.1 \%$ of international pharmacists pass the Pharmacy Qualifying Examination, compared to $91 \%$ of Canadian graduates. When compared to the United Kingdom and United States, Canada has the lowest success rates for the integration of international pharmacists. Aim: This study aims to address two questions: What are the professional pharmacy policies governing the clinical training resources for international pharmacists within their host country? What can Canada learn from other Western countries to facilitate the integration of international pharmacists? Method: A comparative policy analysis was used to draw comparisons between Canada's regulatory policies governing the pharmacy license to other similar models in the United Kingdom and United States. Results: Upon examining current integration systems in these countries, differences in training period requirements and competencies became apparent. Therefore, the findings suggest that Canadian stakeholders can learn from other models' legislation, structure, and clinical outcome prospects.
\end{abstract}

\begin{abstract}
Introduction
Pharmaceutical regulatory bodies have changed policies to emphasise "rigour" by increasing the advanced clinical training (CT) requirements for domestic pharmacy students (Wilson et al., 2006, Association of Faculties of Pharmacy of Canada (AFPC), 2010). The pharmaceutical profession has undergone fundamental changes over the past two decades (Burns, 2008). The pharmacist's role was generally "drug-centred" Nowadays, pharmacists are "patientcentred" and have increased roles in hospitals and specialised clinics (Epstein et al., 2010, Choe et al., 2012). Pharmacy schools have had an essential and dynamic role in supporting the fast progress of the profession by implementing different educational frameworks (American Association of Colleges of Pharmacy (AACP), 2010). This paper reviewed the different professional designations in the three countries. The paper also considered the different
\end{abstract}

approaches for domestic and international pharmacists.

In the United States of America (USA) and Canada, the Pharm.D. is a professional doctorate awarded to students after the completion of a four-year professional programme and a minimum of two to four years of undergraduate study (AACP, 2020). In the United Kingdom (UK), the Master (MPharm.) is a recognised pharmacy degree equivalent to a Masters in pharmacy consisting of four years of post-secondary education plus a one-year internship (CT) prior to the registration exam (Sie et al., 2003). International pharmacists (IPs) are recognised practitioners but form a distinct group in the pharmacy profession. In this article, international pharmacists are defined as people who are qualified as pharmacists in their home country but who are not recognised as licensed pharmacists in a country to which they have emigrated unless they undergo evaluation procedures separate from 
domestic pharmacy graduates. According to immigration rules in the three countries, IPs are either categorised as "immigrant, refugees or some other status" (Immigration, Refugees and Citizenship Canada (IRCC), 2018, Office for National Statistics, 2018, Travel.State.Gov., 2019). Therefore, IPs are commonly known or referred to by the pharmaceutical regulatory bodies as "foreign/overseas or international pharmacists".

CT has become a requirement in leading Western pharmacy schools (Knoer, Eck, \& Lucas, 2016). CT is among the main contributors to establishing a clinically oriented programme such as the Doctor of Pharmacy (Pharm.D.) degree in the USA and Canada (Kehrer, Schindel, \& Mann, 2010). Numerous studies have illustrated the benefits of CT in pharmacy schools and highlighted the benefits of its early introduction within the curriculum (Scheckelhoff et al., 2008). IPs have already finished their degrees and have practised in their home countries. They, therefore, have clinical practice experience in their home countries; however, they lack exposure to domestic clinical practice guidelines and competencies. This experience is essential for passing the regulatory examinations. CT provides first-hand experience for students to undertake patient care such as; medication interviewing and application of patient-care skills (Frankel, Louizos, \& Austin, 2014). Additionally, CT positively correlates with improving a trainee's communication skills leading to an increase in their confidence within the role of health information resource for members of the public (Phillips, Fleming, \& Playdon, 2009).

Various stakeholders in North America, including pharmacy schools, pharmaceutical associations, and other healthcare officials, have led the efforts to standardise CT in the number of credits, contact hours, and training periods that students experience during their educational journey (Hall et al., 2012). According to Delgado, Kernan, and Knoer (2014), students in these advanced pharmacy practice experiences gain experience in applied therapeutics and drug therapy problems in patient assessment, monitoring, and counselling. There is a lack of formal research on integration systems for IPs and specifically on CT within the three countries.

Between 2015-2017, IPs in the USA had a success rate of over $60 \%$ in the qualifying exam (out of 18,189 applicants) (NABP, 2018); the rate was more than $80 \%$ for IPs in the UK during the same period (out of 2,569 applicants) (General Pharmaceutical Council (GPhC), 2018). At the same time, only $41.1 \%$ of IPs in Canada passed on the first attempt (out of 2,156 applications of international graduates), and $50.5 \%$ passed on the second attempt (out of 1,886 applicants), compared to 91\% for graduates of a Canadian-accredited pharmacy programme who passed on the first attempt (from a pool of 2,683 applications) (Pharmacy Examining Board of Canada (PEBC), 2018), as shown in Figure 1. Taken together, these statistics demonstrate a misalignment between Canada's intended goals of existing integration systems for pharmacists and the actual results. There is a systematic difference between domestically trained pharmacists and IPs in Canada that does not exist in similar western countries. This is problematic because Canada would not be able to meet the high demand for pharmacists within its healthcare system (IRCC, 2019) by relying only on domestically educated pharmacists. Implementing strategies to create a higher percentage of successful IPs in Canada can help to alleviate the potential shortage of pharmacists from domestic sources.

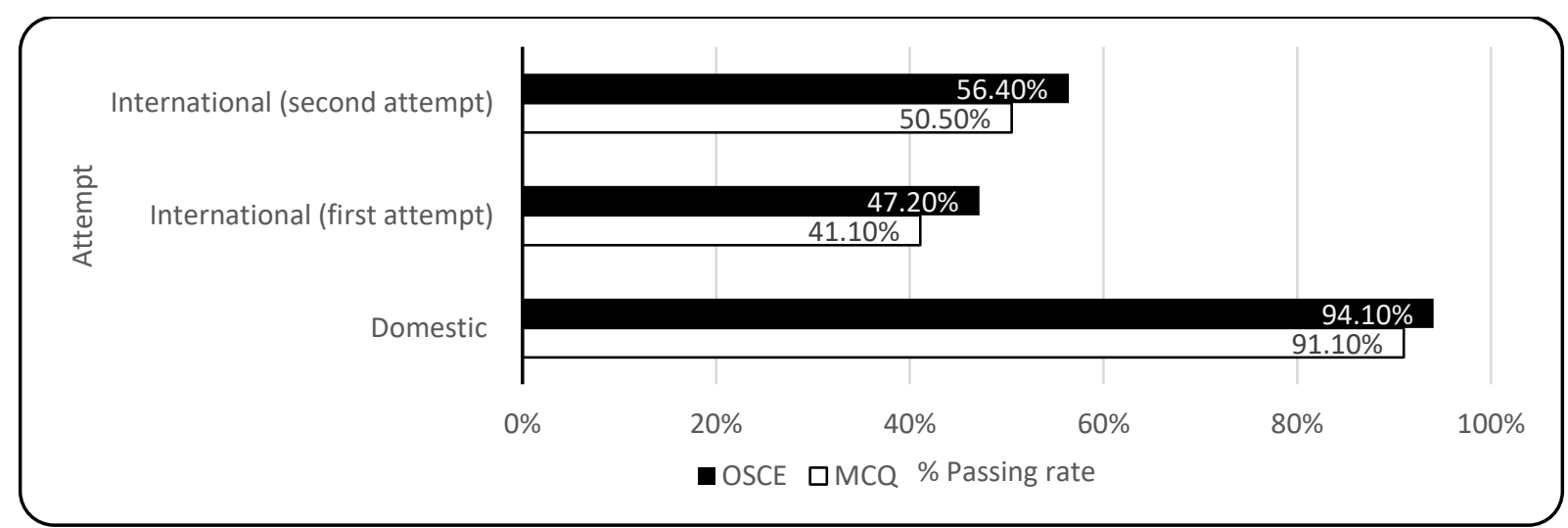

Domestic: graduates of Canadian-accredited pharmacy programmes taking the exam for the first time in the year of graduation. International first attempt: First-Time test takers that are graduates of international (non-USA, non-accredited) pharmacy programmes taking the exam for the first time. International second attempt: Repeat test takers that are graduates of international (non-USA, non-accredited) pharmacy programmes taking the exam who were previously unsuccessful.

Figure 1: Pharmacist qualifying examination Canada 2019 
As the pharmacy profession tries to meet the demands of an increasingly globalised market and rising migration, IPs are struggling to integrate. There is a significant lack of studies defining advanced pharmacy practices and thoroughly examining policies and educational frameworks needed for implementing advanced clinical training for IPs across Canada and other developed countries. Moreover, there is a lack of scholarly work on difficulties for IPs of visible ethnic minorities and studies that focus on barriers affecting these IPs. This paper is the first study to uncover major similarities and differences in educational and regulatory systems of clinical training opportunities for domestic and international pharmacy graduates. This study aims to showcase previously unexamined aspects of inequality between domestic students and IPS, as well as to establish a platform for informed decisionmaking that can guide the efforts of policymakers, senior officials, and educators to improve the integration of IPs into the Canadian pharmacy practice. It is imperative to recognise where Canada's pharmacy integration systems stand relative to others in the USA and UK and understand the professional pharmacy policies governing the clinical training resources for IPS within their host country.

\section{Method}

In this article, a comparative policy analysis of regulators' policies governing pharmacy licenses for IPs and domestic pharmacy students in the three countries was conducted (Shaw, 2004; Owen, 2014). Specifically, a snapshot of the processes, challenges, and realities through real-life events occurring within the licensing systems of the three countries and their effects on IPs' success rates in the licensing examination was captured. This comparative approach in public policy provides a platform for identifying the pitfalls in the current licensing systems. These elements reveal systemic causal mechanisms in the licensing of IPs that need revising to align with the original goals mandated by the established policies to integrate international pharmacists into the pharmacy profession. Through this multi-faceted approach, connections between different actors in the licensing process began to unfold.

The author used an explanatory comparative policy analysis based on Merriam (1998), first in the analysis of policies and procedures in the higher education and healthcare systems in the three countries in CT of pharmacy students and IPs. Additionally, the author completed an analysis of documentation published by various governmental bodies, educational institutes, and regulatory authorities on students' CT and IPS
(Pope, Ziebland, \& Mays, 2000). Data was gathered from websites, quality assurance reports, and publications from conferences or official meetings by the main actors such as federal, state, and provincial pharmaceutical regulatory bodies, regulatory educational institutes, and pharmacy schools present in each country.

The descriptive data was presented through IPs and domestic graduate's passing rates in licensing examinations within each of the three countries during 2015-2017 (based on public data availability). Comparisons are drawn between IPs and domestic pharmacy students in access, academic structure, systemic design, and professional resources. Explanatory data was provided by detailing the policies and procedures dictating licensing procedures for both domestic pharmacists and IPs within each country. The focus is on national systems, where comparisons are drawn between the Canadian model and other similar models such as those of the United Kingdom (UK) and the USA. This is because, according to the United Nations Department of Economic and Social Affairs, Canada, the USA, and the UK have witnessed an increase in immigration over the past two decades, particularly for highly skilled workers in an effort to boost their job markets. Lastly, to understand the depth and breadth of the academic design of CT, the author examined documents and online resources published on various accreditation institutes, quality assurance reports, and ministerial websites.

\section{Results}

In general, licensing procedures to qualify an IP to practice in a new country can be divided into three distinct stages. First is background credentials check, which evaluates the applicant's basic educational background and whether it is enough to pass a threshold of practical and theoretical knowledge to qualify the applicant for the next step. The second stage is the evaluation examination, created and administered by the licensing body, which aims to evaluate the applicant's readiness, knowledge, and proficiency as a pharmacist. In this crucial step, IPs have to recall basic information acquired in their pharmacy schools and become knowledgeable of the basic pharmaceutical information required by the regulatory bodies in competencies or any other educational frameworks. For example, the topics covered by the American Foreign Pharmacy Graduates Equivalency Examination (FPGEE) include the basic knowledge and skills in pharmaceutical sciences such as medicinal chemistry, pharmacognosy, and pharmacology. Applicants who successfully pass these stages are required to undergo a specified period of CT. 
The CT exposes the applicant to real-life situations in a pharmacy setting under the supervision of a licensed pharmacist. This enables the applicant to apply and practice the knowledge and skills gained from dealing with real patients while integrating into the pharmacy practice of that country in therapeutic standards, learning outcomes, ethical protocols, and professional strategies.

\section{USA}

After the completion of the common first step of the credential check, the next step in license recognition in the USA is an English proficiency examination by achieving a minimum score for The Test of English as a Foreign Language (TOEFL) including Reading (22), Listening (21), Speaking (26), and Writing (24) (NABP, 2019). In 1982, the USA National Association of Boards of Pharmacy NABP initiated the Foreign Pharmacy Graduate Examination Committee (FPGEC). The committee developed the Foreign Pharmacy Graduates Equivalency Examination (FPGEE). The IP must finish "the first evaluation examination", which tests their fundamental pharmacy knowledge with a comprehensive competency framework of $10 \%$ on Basic Biomedical Sciences, 33\% on Pharmaceutical Sciences, $22 \%$ on Social/Behavioral/Administrative Sciences, and $35 \%$ on Clinical Sciences (NABP, 2019). If they pass, the IPs are prepared for the next step where the internship starts at a local pharmacy under the supervision of a licensed pharmacist for a period of no less than approximately $1600 \mathrm{hrs}$ (depending on the state) before taking the North American Pharmacist Licensure Examination NAPLEX exam (Vincent, Steinke, \& Fink, 2010). NAPLEX is the final qualifying examination to be a registered practising pharmacist in the USA (Newton, Boyle, \& Catizone, 2008). According to the NABP website, the cost of the application to the FPGEE is 550 USD, an examination fee of 650 USD, and the NAPLEX examination fee of 575 USD, totalling 1775 USD, equivalent to 2367 CAD.

IPs were required to follow the guidelines of the FPGEC. The period of training for both domestic and IPs are comparable in the contact hours practised. However, while these guidelines were meant to be similar to the domestic student experience, some differences are worth noting. For instance, IPs do not have the same opportunities for site placement and interprofessional relations development; the specialised rotation sites offered to IPs are limited to community and hospital pharmacies. Additionally, foreign pharmacists are required to find placements themselves. Consequently, the IPs have limited exposure to healthcare providers, and the only professional source of information is the supervising licensed pharmacist.
In 2006, the USA NABP task force standardised student pharmacist experiential requirements CT at pharmacy educational sites (Vlasses, Wadelin, \& Travlos, 2007). NABP is the main USA legislative body responsible for the regulation of the pharmacy profession through laws and executive mandates. The decision by the NABP necessitated all pharmacy schools seeking Accreditation Council for Pharmacy Education (ACPE) accreditation to incorporate pharmacy practice experiences within their professional curricula. Consequently, this decision led to the revision of the Model State Pharmacy Act and Model Rules of the NABP and came to effect in July 2007 (NABP, 2007). $A C P E$ is the national regulatory body in charge of accreditation requirements recognised by the Council for Higher Education Accreditation (CHEA) and the US Department of Education. It restructured its standards and guidelines to reflect this change and led to the creation of the American Pharm.D. degree.

Pharmacy schools implemented these recommendations through two distinct practical periods: the "introductory" period, consisting of 300 contact hours over three years, and a longer period of "advanced pharmacy practice" with 1440 contact hours in the fourth year of the Pharm.D. degree. The motivation behind these changes was to empower the pharmacy student with a greater depth of knowledge, practical skills, and contextualised professional experience for their professional education in keeping with the evolving nature of the profession. In the introductory period, the pharmacy student practises in a community and hospital setting to develop their practice skills, judgment, professionalism, and personal responsibility to practice independently and/or collaboratively. The practical experience is under the supervision of a preceptor from the academic faculty and a licensed pharmacist, in addition to the support of the regulatory and legislative bodies to ensure the highest standard of patient responsibility (Vincent, Steinke \& Fink, 2010).

The advanced pharmacy practice period (the final year) may be done in a community setting but is more commonly completed in a hospital setting and is generally more clinically oriented, usually including experience in a specialised health-system pharmacy, elderly care clinics, ambulatory care, and inpatient or general medicine. For example, this may include experiences within paediatric, diabetes, as well as various hospital departments such as cardiology and emergency (Dennis et al., 2016). Students are enrolled in eight rotations with placement sites for five weeks each (full time: 40 hours per week), amounting to a minimum of 40 weeks of experiential learning. This experiential CT for domestic students qualifies them to interact with the various professions making up the 
healthcare system (Dugan, 2006; Brackett et al., 2009). The mandates and changes were not restricted to domestic students as the new laws also included infrastructural changes to accommodate for the training of the IPS.

\section{UK}

Britain accommodates IPs into one of five pharmacy schools distributed throughout the UK (GPhC, 2019a). Before entering into the two year-programme, the IP applies for eligibility, including a credentials check and letters confirming professional registration and good standing in their home country. IPs must demonstrate adequate English proficiency with an average of 7.0 on an official examination (International English Language Testing System (IELTS) Academic). The first year of the programme is called 'Overseas Pharmacists' Assessment Programme (OSPAP)", which is a postgraduate diploma providing the applicant with educational and training experience that is required for practice in the UK (GPhC, 2019b). The OSPAP is a fulltime academic structured course consisting of seven modules such as Scientific Basis of Pharmacy Practice, Applied Therapeutics, and Pharmaceutical Skills. The academic course is covered over two semesters where the student has to attend and pass all course assessments successfully. The cost of the course for International full-time students is 12,000 GBP $(21,018$ Canadian dollars). The OSPAP also prepares IPs for the second year during which they are requested to practice at a training site approved by the UK General Pharmaceutical Council GPhC under the supervision of an authorised tutor (licensed pharmacist) for 52 weeks, and can function according to the "Standards for the education and training of non-EEA pharmacists wanting to register in Great Britain" issued by the GPhC. At the end of that period, the IPs have to pass the registration assessment to be recognised as fully-fledged practising pharmacists.

In the UK, experiential learning is termed "practical experience." A survey conducted by Wilson and authors in 2006 found that practical experience is conducted by most pharmacy schools. The practical experience period was mainly conducted in hospitals during the final year of the MPharm. Degree. However, the duration of the period differed from one school to the other, ranging from a few hours to 16 days. In 2011, experiential learning became a requirement for all students to meet the standards for "initial education and training of pharmacists" guidelines recommended by the GPhC (GPhC, 2011). Additionally, the council recommended increasing the duration of practical experience and the number of tutors and placement sites available for students to better serve their educational needs and meet educational objectives. In
2019, Jacob and Boyter reported that the number of hours of experiential clinical learning had increased over the years, and placement sites to accommodate the number of students as well as different modules had grown accordingly; however, the authors stated that more standardisation is needed in training procedures, tutor development and quality assurance for future advancements.

Similar to the American approach in implementing FPGEC guidelines (2005), the UK's RPSGB, and in 2010 the GPhC, mandated IPs to undertake the OSPAP followed by a year's pre-registration training to be qualified for the license to practice (Schafheutle \& Hassell, 2009). This enables overseas pharmacists to have an equivalent educational experience to domestic graduates. Of particular importance, the preregistration year allows both foreign and domestic graduates to undertake practical pharmacy practice either in a community or hospital setting under the supervision of a licensed pharmacist. For this reason, both domestic and overseas applicants are provided with the opportunity to apply the knowledge and skills gained during their study, and consequently, the foreign pharmacy graduate will become familiar with the British healthcare system's guidelines and procedures related to pharmacy practice in the UK.

Currently, in the UK, clinical experience is initiated in the pharmacy programme. However, the majority of the clinical experience is gained after the student graduates and starts working in a community or hospital setting or some other healthcare practice setting prior to the registration examination.

\section{Canada}

Within Canada, IPs have to first pass the credential check and obtain a letter of good standing from the licensing body in their home country. In 2014, the PEBC collaborated with the National Association of Pharmacy Regulatory Authority (NAPRA) to facilitate the registration of the IPs to establish a programme called Pharmacists' Gateway Canada. Secondly, IPs are required to finish the evaluation examination, which tests their fundamental pharmacy knowledge. The syllabus for the evaluating examination is similar to the U.S. in its four major subject areas and also includes professional practice skills. After successful completion, the IPs advance to the final qualifying examination administered by the PEBC to be a registered practising pharmacist. This examination is composed of two sections, including multiple-choice questions and an Objective Structured Clinical Examination (OSCE) (PEBC, 2019). The examination is based on the 2014 NAPRA professional competencies for Canadian pharmacists (2014) at the entry to 
practice, including nine competencies: ethical, legal and professional responsibilities, patient care pharmacists, intra and inter-professional collaboration pharmacists, and quality and safety pharmacists (NAPRA, 2014; PEBC, 2019). According to the PEBC website, the cost for the necessary steps includes the document evaluation (300CAD), evaluating examination (535 CAD), and qualifying examination (1990 CAD).

Subsequent to the changes implemented by the USA, Canada's response was to establish a task force in 2007 to define and design the framework necessary for the successful introduction of the Pharm.D. degree to Canadian pharmacy schools (CPA, 2008). The task force set out by the CPA represented stakeholders in pharmacy practice, education, and various regulatory bodies for the profession to address challenges in the shift from a drug-centred to patient-centred philosophy in pharmacy (CPA, 2009). The task force defined new requirements for obtaining the pharmacy license, including the completion of the national certification examination (administered by the PEBC), and encouraged the implementation of structured practical training as part of these requirements (Association of Faculties of Pharmacy of Canada (AFPC) and Association of Deans of Pharmacy of Canada (ADPC), 2010). While the task force's report was addressed to both domestic and international applicants to the pharmacy practice, there are key differences in how the transition was to pan out for these applicants (CPA, 2008).

Key action points and goals were highlighted to address the needs of domestic applicants, such as an increase in clinical experience within hospitals by mandating the creation of experiential clinical training opportunities within pharmacy school curricula (AFPC, 2010). Shortly after, in 2010, the CPA supported the joint resolution of the AFPC and the ADPC on the Pharm.D. to be the first professional pharmacy degree at universities in Canada (CPA, 2011). This decision commits faculties to replace their current Baccalaureate Pharmacy curricula with a comprehensive Pharm.D. curriculum. In response, the Canadian Council for Accreditation of Pharmacy Programmes (CCAPP) (2014) amended their accreditation standards to be in line with the USA pharmacy colleges. This included a minimum of 44 weeks (1700 hours) of experiential time which has to be adopted by pharmacy schools for accreditation.

Experiential clinical learning experiences consisted of at least eight weeks of practice in a community setting and 36 weeks of 1440 hours of advanced pharmacy practice experiences covered during the third and fourth year of the Pharm.D. programme, primarily in a community and hospital setting. This experiential clinical learning would expose the students not only to the different pharmacy practice sites but also to interprofessional interactions with physicians of different specialities, nurses, and other healthcare professionals.

IPs applicants were assigned to six bridging programmes set up across Canada, and it was the bridging programmes' responsibility to address the task force's new requirements and allow for a successful transition and integration of IPs into Canada. Additionally, it was the responsibility of universities and national regulatory bodies such as NAPRA, CCAPP, and $P E B C$ to ensure the successful integration of IPs, but the onus fell on each provincial regulatory body to decide how to best approach this issue (CPA, 2009). The bridging programmes help familiarise IPs with different professional roles, regulatory requirements, and client services by increasing professional and social interaction (NAPRA, 2019).

In contrast, IPs have no defined CT learning, unlike the structured experiential learning undertaken by domestic students in Canada. Meanwhile, the evaluation tools and assessment criteria continued to evolve. For instance, in 2018, after multiple standardisations and pilot testing periods (from 2014 to 2017), the Practice Assessment of Competence at Entry (PACE) procedure (Structured Practical Training SPT) was approved and mandated as a requirement for successful international pharmacy graduates within Canada. Therefore, while an assessment tool was implemented, no assessment module necessitating experiential CT or outlining practical learning hours exists as part of the learning programmes offered to international graduate pharmacists. Consequently, international graduates are expected to fulfil the same learning requirements as domestic students, but unlike the latter, they are not offered the same immersion opportunities into the profession. There are different reciprocal agreements for each licensing body, each with different requirements. Licensing procedures for domestic and IPs are summarised in Table I and Table II, and three elements of clinical experience, interprofessional education, and mentorship (training resources) for domestic pharmacy students in the three countries, as shown in Table III. 
Table I: Licensing procedures for domestic pharmacy graduates across the three countries

\begin{tabular}{lllc}
\hline \multicolumn{1}{c}{ Country } & \multicolumn{1}{c}{ Canada } & USA & UK \\
\hline $\begin{array}{l}\text { Licensing } \\
\text { procedures } \\
\text { for }\end{array}$ & $\begin{array}{l}\text { Completion of an approved pharmaceutical } \\
\text { education programme }\end{array}$ & $\begin{array}{l}\text { A board-approved pharmacy } \\
\text { degree programme }\end{array}$ & UK Accredited MPharm \\
$\begin{array}{l}\text { domestic } \\
\text { pharmacy } \\
\text { graduates }\end{array}$ & Qualifying examination (MCQ) and OSCE & After graduation directly & Pass the NAPLEX (Written) \\
\cline { 2 - 4 } & & & $\begin{array}{l}\text { 1.52 weeks of pre-registration training } \\
\text { 2. Pass the pharmaceutical council } \\
\text { registration assessment }\end{array}$
\end{tabular}

Information was gathered from the pharmacy regulatory websites PEBC, NABP, and UK GPhC

Table II: Licensing procedures for international pharmacy graduates across the three countries.

\begin{tabular}{|c|c|c|c|c|c|}
\hline Step & Component & Canada & USA & \multicolumn{2}{|l|}{ UK } \\
\hline 1 & $\begin{array}{l}\text { Document } \\
\text { evaluation }\end{array}$ & $\begin{array}{l}\text { Pharmacist Gateway Canada, } \\
\text { including } \\
\text { credential check, practice } \\
\text { experience }\end{array}$ & $\begin{array}{l}\text { The Foreign Pharmacy Graduate } \\
\text { Equivalency Examination } \\
\text { (FPGEC) Program, including } \\
\text { credential check, practice } \\
\text { experience, language proficiency } \\
\text { (mandatory) }\end{array}$ & \multicolumn{2}{|c|}{$\begin{array}{l}\text { Overseas Pharmacists Assessment } \\
\text { Programme (OSPAP) includes: } \\
\text { English language, assessment of } \\
\text { qualifications, attending the specific } \\
\text { courses in the assigned universities }\end{array}$} \\
\hline 2 & & $\begin{array}{l}\text { PEBC evaluation examination } \\
\text { The Practice Assessment of } \\
\text { Competence at Entry (PACE) } \\
\text { Structured Practical Training (SPT). } \\
\text { Ontario } 3 \text { weeks } \\
\text { Alberta: } 1000 \text { hours. BC: } 24 \text { Weeks } \\
\text { (500 hrs) }\end{array}$ & $\begin{array}{l}\text { Foreign Pharmacy Graduate } \\
\text { Equivalency Examination (FPGEE). } \\
\text { A of a minimum of } 1600-1860 \mathrm{hrs} \\
\text { depending on the state. }\end{array}$ & \multicolumn{2}{|c|}{$\begin{array}{l}52 \text { weeks of pre-registration training } \\
\text { applicable for all applicants across } \\
\text { the UK }\end{array}$} \\
\hline 3 & $\begin{array}{l}\text { Qualifying } \\
\text { examination }\end{array}$ & $\begin{array}{l}\text { Passing PEBC Qualifying Examination } \\
\text { part } 1 \mathrm{MCQ} \text {, part } 2 \text { OSCE† }\end{array}$ & $\begin{array}{l}\text { Passing the written examination } \\
\text { of the North American Pharmacist } \\
\text { Licensure Examination (NAPLEX) }\end{array}$ & \multicolumn{2}{|c|}{$\begin{array}{l}\text { Passing the written examination of } \\
\text { the } \mathrm{GPhC} \text { registration assessment }\end{array}$} \\
\hline \multicolumn{6}{|c|}{$\begin{array}{l}\text { Note: Jurisprudence Examinations are part of the licensing procedures and have to be completed after the examinations, with other administrative procedures, and } \\
\text { language proficiency. } \\
\text { +OSCE: Objected Structured Clinical Examination. }\end{array}$} \\
\hline \multicolumn{2}{|c|}{$\begin{array}{l}\text { Training } \\
\text { resources }\end{array}$} & USA & Canada & & UK \\
\hline & & \multicolumn{4}{|c|}{ Before graduation } \\
\hline \multicolumn{2}{|c|}{$\begin{array}{l}\text { Clinical experiential } \\
\text { learning }\end{array}$} & $\begin{array}{l}\text { 1) } 300 \text { hours introductory pharmacy practice } \\
\text { experiences over the first three professional } \\
\text { years, balanced between institutional and } \\
\text { community pharmacy practice. } \\
\text { 2) in the final academic year (year 4), } 1440 \\
\text { hours ( } 36 \text { weeks) of advanced pharmacy } \\
\text { practice experiences }\end{array}$ & $\begin{array}{l}\text { Similar to the USA } \\
44-46 \text { weeks consisting of } \\
\text { 1) 10-12 weeks in the first and } \\
\text { second year with "Early Practice } \\
\text { Experience" } \\
\text { 2) } 36 \text { weeks in advance } \\
\text { community, hospital, and } \\
\text { ambulatory clinic or other types } \\
\text { patient care practices }\end{array}$ & s of & $\begin{array}{l}52-419 \text { hours in a clinical } \\
\text { settings to develop and give } \\
\text { context for skill development }\end{array}$ \\
\hline \multicolumn{2}{|c|}{$\begin{array}{l}\text { Interprofessional } \\
\text { education }\end{array}$} & $\begin{array}{l}\text { Different healthcare professionals such as } \\
\text { nurses, and doctors }\end{array}$ & \multicolumn{2}{|l|}{$\begin{array}{l}\text { Different healthcare professionals } \\
\text { such as nurses, and doctors }\end{array}$} & $\begin{array}{l}\text { Different healthcare } \\
\text { professionals such as nurses, } \\
\text { and doctors }\end{array}$ \\
\hline \multicolumn{2}{|c|}{$\begin{array}{l}\text { Mentorship of } \\
\text { pharmacy students }\end{array}$} & Present & Present & & Present \\
\hline \multicolumn{6}{|c|}{ After graduation } \\
\hline \multicolumn{3}{|c|}{$\begin{array}{l}\text { Clinical experiential } \\
\text { learning }\end{array}$} & & \multicolumn{2}{|r|}{$\begin{array}{l}52 \text { weeks in a pharmacy } \\
\text { setting }\end{array}$} \\
\hline \multicolumn{2}{|c|}{$\begin{array}{l}\text { Interprofessional } \\
\text { education }\end{array}$} & & & & Present \\
\hline \multicolumn{3}{|c|}{$\begin{array}{l}\text { Mentorship of } \\
\text { pharmacy students }\end{array}$} & \multicolumn{2}{|c|}{ Present } & \\
\hline
\end{tabular}




\section{Discussion}

The purpose of this paper was to demonstrate the differences and similarities between regulatory bodies' requirements towards IPs. Examination of the websites published by regulatory bodies shows similarities in procedures used to evaluate and validate the IP's knowledge, skills, and attitude towards pharmacy practice in a western environment. Meanwhile, differences between regulatory bodies arise in their emphasis on the need for clinical experience during the IP's preparatory period of the licensing process. These differences are apparent in the availability of options to conduct such an experience and the infrastructure provided in training sites, mentorship structure, and interprofessional interactions.

The credentials check for IPs uses a number of criteria to evaluate the IPs' application, including the length of the programme from which the applicant graduated. For example, applicants coming from countries that have a four-year programme find difficulties in being accepted according to the North American Pharmacy school requirements as they stipulate graduation from a five-year programme or five years worth of studies. Indeed, this varies between countries and within different states of the same country depending on accreditation standards used to assess the validity of different programmes.

The majority of IPs in Canada have at least three to five years of professional experience in their home country after graduation (Canadian Institute for Health Information, 2019). Applicants are required to provide a letter of evidence for professional experience and good standing of practice for a minimum of one to two years in the IP's home country. One of the barriers involved in the previous process is that the IP has to arrange the transfer of the official graduating manuscripts and letters of good standing from the home country directly to the relevant office of the Western regulatory body. This process, if possible, is costly and time-consuming. Additionally, many countries do not have the facilities and infrastructure necessary to comply with the IP's request, which leads to their exclusion from the application process.

Even with these uncertainties, the onus of the transfer process is entirely left to the applicant as they have to mediate communication between the regulatory bodies and the institutions in their home country; another obstacle, which IPs have to surmount for their application to be considered. This issue is exacerbated if the IPs, at the time of application, are a resident of a country other than their home country. This means that there is no physical way for the applicant to book appointments or inquire about their application in person in their previous country.
English proficiency is a primary requirement in the initial stages of the registration process, except in Canada. The IP is mandated to prepare and undertake a language proficiency test which requires both time and money to achieve the required standards set out by the regulatory bodies. Data published by the IELTS indicates that a score of seven (the minimum required by regulatory bodies in each category) is relatively low to achieve, and it might need more than one to two attempts for individuals coming from countries where English is not the first language, based on statistics published by IELTS by country of origin and candidate's first language.

Finally, passing through the first evaluating examination is another obstacle for IPs for a number of reasons related to academic aid and exam location. First, in the USA and Canada, there is no preparatory schooling for the IPs before the evaluating examination. The IPs are faced with a difficult obstacle because the amount and breadth of knowledge that is necessary to pass the exam is left to the IPs and their ability instead of an organised curriculum that can be reviewed and studied in advance under the supervision of trained professors and professionals. Despite the availability of preparatory schooling in the UK, access to the five schools is problematic for IPs due to academic eligibility criteria and financial commitments $(27,000$ CAD for the programme). Pharmacy schools have designed their continuing education curricula so their students can achieve the required competencies set out by regulatory bodies and ensure fast entry to practice. In general, providing CT experience through collaborations between pharmacy schools, regulatory bodies, and hospitals shows the importance and necessity of CT not only to enrich the practical experience for domestic graduates but to achieve the competencies required by regulatory bodies for domestic students to pass the licensing examination.

Furthermore, this structure enables the domestic student and graduates to approach the final examination for licensing immediately after completion of their clinical experience, thereby reducing the cost and time needed to pass the licensing examination. This is in stark contrast to the IPs, where the structure provided for their CT (if it is even available) is different, and additional regulatory mandates lead to an increased economic burden and an indeterminant amount of time commitment. The formulation of this clinical experience often and in various ways privileges domestic pharmacy students over IPs and is the core of inequality amongst the three countries. Each country has its own design and vision on how the experience should look. Differences appear in structure, access, and clinical outcomes achieved through the CT period. 
In North America, the CT experience (approximately 1700 hours) is completed during the student's study period in pharmacy school. However, in the UK, clinical experience is undertaken mainly after the student's graduation through a one-year pre-registration requirement mandated by the regulatory bodies. However, the domestic student can still complete 50500 hours of clinical experience during their study period in pharmacy school, depending on the school and programme they attend.

In the UK, the CT experience is more equal because it is structured similarly for both domestic and IPs. Both undergo their clinical experience for the same duration and under the same professional circumstances. Professional circumstances refer to the type of training sites where both IPs and domestic students are exposed to the same mentorship under the pharmacist in charge and interprofessional interactions within the pharmacy site. The domestic and IPs are known as "interns," and the pharmacist in charge is responsible for assisting and familiarising interns with the procedures and protocols of the pharmacy profession through real-life situations. The mentorship offered by the pharmacist-in-charge is conducted under a scheduled manual given out by the regulatory bodies and applied within a specific timeframe.

In North America, the model is different because domestic students are subjected to a rigorous curriculum and formal CT period as part of their Pharm.D. degree. The CT includes placing the students in a number of pharmacy practice sites in hospitals and community settings. On the other hand, the IPs in the USA have a required training period to accomplish, but the training site and experience are mainly limited to the community setting due to the lack of professional networking and domestic opportunities in placements.

The intern in the UK is able to interact with patients and offer advice on their medication's appropriateness, efficiency, and side effects. When the intern has progressed through their training, they are able to take on more advanced roles which focus on person-centred care, including patient assessment and professional guidance on health issues such as asthma, diarrhoea, and joint pain. Interprofessional interaction is limited for both domestic and IPs because the majority of practising sites are within a community setting, where fewer interaction opportunities are available as compared to a hospital setting. In a hospital, the intern interacts with different medical staff at different levels of speciality within different medical fields, and this enriches the $\mathrm{CT}$ for the intern. It should be noted that even with this similarity, there is still an advantage for domestic graduates over IPs: when applying to hospitals, domestic students could have already begun building their interprofessional relationships during their degree programme. The mentorship and interprofessional interaction in the UK are still less diverse in specialities and depth in professional relationships than the North American model (Jacob \& Boyter, 2019).

In the USA, the domestic student is allowed to deal with real-life situations and fulfils an active role as part of the pharmacy team. For example, the students can decide on drug appropriateness for patients with a number of chronic diseases. Students can initiate, modify, and monitor a patient's drug therapy plan and can be allowed to administer certain specialised medications. On the other hand, IPs do not have the same rigorous experience in practice, advanced training sites, and curriculum design. Very few IPs have access to advanced hospital settings because of their lack of domestic pharmacy experience and the absence of professional networking because they had no formal training with hospital sites beforehand. Consequently, roles carried out by the IPs are also limited to preparatory and superficial interactions with patients.

The mentorship and interprofessional interaction in the USA for domestic students during their CT are under the supervision of a number of trained preceptors. The preceptors are either from academic or pharmacy backgrounds in different specialities across the pharmacy practice spectrum. Additionally, during the clinical experience, the domestic pharmacy student is exposed to a number of other healthcare personnel, such as doctors and nurses, who enrich the learning process of the student. This is not the case for IPS because the experience is mostly in a community setting with access only to the pharmacist-in-charge.

In Canada, the situation is similar to the U.S. for domestic students. Students are provided with access to advanced $\mathrm{CT}$, diverse mentorship supervision, and opportunities for interprofessional interactions with different medical specialities. Additionally, before graduation, domestic students are able to practice advanced roles and gain experience with patients in both hospital and community pharmacy settings. The situation for IPs is completely different due to the lack of legislation for CT as present in the other countries. The three stakeholders, including pharmacy regulatory bodies, pharmacy schools, and pharmaceutical associations, have left the decision to the bridging programmes present in Canada to decide the needs of IPs in the Canadian pharmacy practice. Scattered recent efforts from local regulatory bodies have initiated training experiences for IPS as part of their requirements for registration in Alberta and British Columbia. However, these efforts lack duration, mentorship diversity, and interprofessional interaction 
present in the other countries. The lack of exposure to the clinical atmosphere has limited the integration of IPs into Canadian pharmacy practice.

\section{Limitations}

This study has several limitations. First, there is a lack of demographic data available on the number of IPS passing the final qualifying examination over the past ten years, and other types of data such as age, gender, previous pharmacy degree acquired, and years of experience in the country of origin. Second, semistructured interviews with senior officials and educators from various pharmacy institutes involved would enrich our understanding of how policymakers and educators value clinical training for pharmacy students and IPs.

\section{Conclusion}

It is important that as we continue to build on our understanding of the professions and professional education that we critically examine the professional educational directions being taken and try to continuously reexamine our frame of reference: see what works, what does not, and how we can enhance the system. The competencies established by the Canadian pharmacy regulatory bodies often serve as exclusion criteria for the IPs compared to the Canadian pharmacy graduates to bolster the dominant group status and keep the subordinate group (non-Canadian pharmacy graduates) at a disadvantage. Firstly, new directions need to be centred on the minimisation of exclusion criteria and expansion of inclusion criteria. To break away from this, Canadian stakeholders have to make a better effort by either modifying their measure of competencies (exclusion criteria) to better recognise clinical experiences from non-Canadian settings, or universities can make a better effort in continuously updating and examining their existing curricula in programmes for IPs to include CT experiences similar to the domestic pharmacy students to ease the incorporation of international graduates into the Canadian healthcare systems. Canadian Pharmacy regulatory bodies could focus on implementing a set number of hours and adjusting the timing for CT. This is because there is no legislative infrastructure mandating training in a clinical setting (hospital and community setting) for IPs in Canada. Additionally, CT could take place before the final qualifying examination (similar to how it is done in the two other countries).

There also needs to be a system re-examination of what these inclusion and exclusion criteria may mean to people of different races, ethnicities, and socioeconomic statuses. This re-examination cannot be done by educational institutes alone as they do not often have the power to affect policy, and this instead calls for legislative support by the state as well. Therefore, professional education in a time of greater openness in the internationalised era and rapid expansion in globalisation requires professional bodies to be more aware of their boundaries and to cater for as many people as possible with their various experiences and knowledge. This entails a global standard for professions that all regions can abide by and would require political support from legislative powers.

\section{Acknowledgement:}

The author acknowledges, with appreciation, the ongoing support and supervision of Professor Elizabeth Buckner and the revision of the article by Professor Gavin Moodie.

\section{References}

Accreditation Council for Pharmacy Education (ACPE). (2007). Standards 2007 Self-Study Guide. Available at: https://www.acpe-

accredit.org/pdf/S2007Guidelines2.0_ChangesIdentifiedlnRed.pdf

Accreditation Council for Pharmacy Education. (ACPE). (2006). Accreditation Standards and Guidelines for the Professional Programme in Pharmacy Leading to the Doctor of Pharmacy Degree. Available at: https://www.acpeaccredit.org/pdf/Standards2016FINAL.pdf

American Association of Colleges of Pharmacy (AACP). (2004). Educational Outcomes 2004. Available at: https://www.aacp.org/sites/default/files/2017-11/CombinedCAPE-2004-Supplemential-Educational-Outcomes.pdf

American Association of Colleges of Pharmacy (AACP). (2020). Who we are. Available at: https://www.aacp.org/article/who-we-are

American Association of Colleges of Pharmacy(AACP). (2010). Annual Report. American Journal of Pharmaceutical Education, Volume 74, Issue 10, Article S3 https://doi.org/10.5688/aj7410S3

Association of Faculties of Pharmacy of Canada (AFPC) and Association of Deans of Pharmacy of Canada (ADPC). (2010). Position Statement and Joint Resolution on the Doctor of Pharmacy (PharmD) for the First Professional Degree at Universities in Canada. Available at: https://www.afpc.info/sites/default/files/AFPC_ADPC_PharmD_ Position_Statement_Resolution_Sept_2010.pdf

Association of Faculties of Pharmacy of Canada. (AFPC) (2010). Educational Outcomes for First Professional Degree Programmes in Pharmacy (Entry-to-Practice Pharmacy Programmes) in Canada. Available at: 
https://www.afpc.info/system/files/public/AFPCEducational\%20 Outcomes\%202017_final\%20Jun2017.pdf

Brackett, P.D., Byrd, D.C., Duke, L.J., Fetterman, J.W., Unterwagner, W.L., Staton, A.G., \& Stevenson, T.L. (2009). Barriers to expanding advanced pharmacy practice experience site availability in an experiential education consortium. American journal of pharmaceutical education, 73(5), 82. https://doi.org/10.5688/aj730582

Burns, A. (2008). Medication therapy management in pharmacy practice: core elements of an MTM service model (version 2.0). Journal of the American Pharmacists Association, 48(3), 341-353. https://doi.org/10.1331/JAPhA.2008.08514

Canadian Institute for Health Information (CIHI). (2019). Table 2, Supply and workforce of health care providers, by type of provider and jurisdiction, for selected provinces/territories, 2008 to 2017. Available at:

https://secure.cihi.ca/estore/productSeries.htm?pc=PCC56

Canadian Pharmacists Association (CPA). (2008). Task Force on a Blueprint for Pharmacy. Blueprint for Pharmacy: The Vision for Pharmacy. Ottawa (ON). Available at:

https://www.pharmacists.ca/cpha-ca/assets/File/pharmacy-incanada/blueprint/The\%20Vision\%20for\%20\%20Pharmacy_Apr\% 201\%2009.pdf

Canadian Pharmacists Association (CPA). (2011). CPhA Position Statement on a Doctor of Pharmacy Degree as an Entry-Level to Practice. Available at: http://www.pharmacists.ca/cphaca/assets/File/cpha-on-the-issues/PPDoctorOfPharmacyEN.pdf

Canadian Pharmacists Association (CPA).(2008). Management Committee, Moving Forward: Pharmacy Human Resources for the Future. Final Report. Ottawa (ON). Available at: https://www.hhrrhs.ca/en/?option=com_mtree\&task=att_download\&link_id=4506\&cf id $=68$

Canadian Pharmacists Association. (CPA). (2016). Research Report. Toward an optimal future: priorities for action, Intergage Consulting Group Inc. Available: https://www. pharmacists.ca/cphaca/assets/File/pharmacy-in-

canada/Thought\%20Leadership\%20Summit\%20Research\%20Repor t_01.pdf

Choe, H.M., Farris, K.B., Stevenson, J.G., Townsend, K., Diez, H.L., Remington, T.L., \& Standiford, C.J. (2012). Patient-centered medical home: developing, expanding, and sustaining a role for pharmacists. American Journal of Health-System Pharmacy, 69(12), 1063-1071. https://doi.org/10.2146/ajhp110470

Delgado, O., Kernan, W.P., \& Knoer, S.J. (2014). Advancing the pharmacy practice model in a community teaching hospital by expanding student rotations. American Journal of Health-System Pharmacy, 71(21), 1871-1876. https://doi.org/10.2146/ajhp130624

Dennis, V.C., May, D.W., Kanmaz, T.J., Reidt, S.L., Serres, M. L., \& Edwards, H.D. (2016). Pharmacy Student Learning During Advanced Pharmacy Practice Experiences in Relation to the CAPE 2013 Outcomes. American journal of pharmaceutical education, 80(7), 127. https://doi.org/10.5688/ajpe807127

Dugan B.D. (2006). Enhancing community pharmacy through advanced pharmacy practice experiences. American journal of pharmaceutical education, 70(1), 21. https://doi.org/10.5688/aj700121
Epstein, R.M., Fiscella, K., Lesser, C.S., \& Stange, K.C. (2010). Why the nation needs a policy push on patient-centered health care. Health affairs, 29(8), 1489-1495. https://doi.org/10.1377/hlthaff.2009.0888

Frankel, G., Louizos, C., \& Austin, Z. (2014). Canadian educational approaches for the advancement of pharmacy practice. American journal of pharmaceutical education, 78(7), 143. https://doi.org/10.5688/ajpe787143

General Pharmaceutical Council (GPC). (2011). Future pharmacists Standards for the initial education and training of pharmacists. Available at:

https://www.pharmacyregulation.org/sites/default/files/docum ent/gphc_future_pharmacists_may_2011.pdf

General Pharmaceutical Council (GPhC). (2019a). Accredited OSPAP courses. Available at:

https://www.pharmacyregulation.org/education/approvedproviders-education-and-training/accredited-ospap-courses

General Pharmaceutical Council (GPhC). (2019b). Overseas (nonEEA) qualified pharmacists. Available at: https://www.pharmacyregulation.org/registration/registeringpharmacist/overseas-non-eea-qualified-pharmacists

General Pharmaceutical Council (GpHC). (2018). June 2017 Registration Assessment performance breakdown, 1st attempt by education route. Available at:

https://www.pharmacyregulation.org/sites/default/files/201709-07_-

_17.09.c.02a_june_2017_performance_breakdown_by_charact eristic.pdf

Hall, K., Musing, E., Miller, D.A., \& Tisdale, J.E. (2012). Experiential training for pharmacy students: time for a new approach. The Canadian journal of hospital pharmacy, 65(4), 285-293. https://doi.org/10.4212/cjhp.v65i4.1159

Immigration, Refugees and Citizenship Canada (2019). Departmental Plan 2018-2019. Available at: https://www.canada.ca/en/immigration-refugeescitizenship/corporate/publications-manuals/departmental-plan2018-2019/departmental-plan.html

Immigration, Refugees and Citizenship Canada. (2018). Annual Report to Parliament on Immigration. Available at: https://www.canada.ca/content/dam/ircc/migration/ircc/englis h/pdf/pub/annual-report-2018.pdf

Jacob, S.A., \& Boyter, A.C. (2019). Nationwide survey of experiential learning in MPharm programmes in UK Universities. International Journal of Pharmacy Practice. https://doi.org/10.1111/ijpp.12521

Kehrer, J.P., Schindel, T.J., \& Mann, H.J. (2010). Cooperation in pharmacy education in Canada and the United States. American journal of pharmaceutical education, 74(8), 142. https://doi.org/10.5688/aj7408142

Knoer, S.J., Eck, A.R., \& Lucas, A.J. (2016). A review of American pharmacy: education, training, technology, and practice. Journal of pharmaceutical health care and sciences, 2, 32. https://doi.org/10.1186/s40780-016-0066-3

Merriam, S.B. (1998). Qualitative research and case study applications in education. San Francisco, CA: Jossey-Bass. 
National Association of Boards of Pharmacy (NABP). (2018). North American Pharmacist Licensure Examination Passing Rates for 2015-2017 Graduates Per Pharmacy School. Available at: https://nabp.pharmacy/wp-content/uploads/2018/02/NAPLEXPass-Rates-2017.pdf

National Association of Boards of Pharmacy (NABP). (2019). The FPGEC Certification Programme. Available at: https://nabp.pharmacy/wp-content/uploads/2019/02/FPGECApplication-Bulletin-February-2019.pdf

National Association of Pharmacy Regulatory Authorities (NAPRA). (2007). Professional Competencies for Canadian Pharmacists at Entry to Practice. Available at: https://napra.ca/sites/default/files/201709/Entry_to_Practice_Competencies_March2007_final_new_lay out_2009.pdf

National Association of Boards of Pharmacy. (2007) newsletter Number 10. Available at: https://nabp.pharmacy/wpcontent/uploads/2016/07/NovDec07NABP.pdf

National Association of Pharmacy Regulatory Authorities (NAPRA). (2019). Pharmacists' Gateway Canada for International Pharmacists. Available at:

http://www.pharmacistsgatewaycanada.ca/

National Association of Pharmacy Regulatory Authorities (NAPRA). (2014). Professional competencies for Canadian pharmacists at entry to practice. Ottawa (ON). Retrieved from Available at : https://napra.ca/sites/default/files/2017-

08/Comp_for_Cdn_PHARMACISTS_at_EntrytoPractice_March2014_b .pdf

Newton, D.W., Boyle, M., \& Catizone, C.A. (2008). The NAPLEX: evolution, purpose, scope, and educational implications. American journal of pharmaceutical education, 72(2), 33. https://doi.org/10.5688/aj720233

Office for National Statistics (ONS). (2018). International migration statistics for the UK for the year ending June 2018. Available at:

https://www.ons.gov.uk/peoplepopulationandcommunity/popu lationandmigration/internationalmigration/bulletins/migrationst atisticsquarterlyreport/november2018

Ontario College of Pharmacists, (2018). Practice Assessment of Competence at Entry (PACE). Available at:

http://www.ocpinfo.com/registration/registrationrequirements/pace-2/

Owen, G. T. (2014). Qualitative Methods in Higher Education Policy Analysis: Using Interviews and Document Analysis. The Qualitative Report, 19(26), 1-19. https://doi.org/10.46743/2160$3715 / 2014.1211$

Peter H. Vlasses, Jeffrey W. Wadelin, and Dimitra V. Travlos (2007). Annual Report of the Accreditation Council for Pharmacy Education. American Journal of Pharmaceutical Education, 71 (2), 37 https://doi.org/10.5688/aj710237

Pharmacy Examining Board of Canada (PEBC). (2018). Performance of domestic and IP on the Pharmacist Qualifying Examination 2016-2018. Available at: https://www.pebc.ca/index.php/ci_id/3114/la_id/1.htm

Pharmacy Examining Board of Canada (PEBC). (2019). Document Evaluation - General Information. Available at: https://www.pebc.ca/index.php/ci_id/3114/la_id/1.htm
Pharmacy Examining Board of Canada (PEBC). (2019). Pharmacist Evaluating Examination, Pharmacist Evaluating Examination Syllabus. Available at: https://www.pebc.ca/index.php/ci_id/3122/la_id/1.htm

Pharmacy Examining Board of Canada (PEBC).(2018). Home, news. Available at:

https://www.pebc.ca/index.php/ci_id/3374/la_id/1.htm

Phillips, B., Fleming, G. \& Playdon, Z. (2009) A strategy for a preregistration quality management training programmeme. Pharmaceutical Journal, 283, 307-309

Pope, C., Ziebland, S., \& Mays, N. (2000). Analysing qualitative data. Bmj, 320(7227), 114-116. https://doi.org/10.1136/bmj.320.7227.114

Scheckelhoff, D.J., Bush, C.G., Flynn, A.A., Myers, C.E., Kahaleh, A.A., Knapp, K.K., \& Thompson, B.J. (2008). Capacity of hospitals to partner with academia to meet experiential education requirements for pharmacy students. American journal of health-system pharmacy, 65(21), e53-71. https://doi.org/10.2146/ajhp080150e

Sie, D., Bates, I., Aggarwal, R., \& Borja-Lopetegi, A. (2003). An analysis of the new UK Master of Pharmacy degree programmeme: Rhetoric and reality. Pharmacy Education, 3(3). https://doi.org/10.1080/1560221031000147557

Shaw, K. M. (2004). Using feminist critical policy analysis in the realm of higher education: The case of welfare reform as gendered educational policy. The Journal of Higher Education, 75(1), 56-79. https://doi.org/10.1080/00221546.2004.11778896

Schafheutle, E.I., \& Hassell, K. (2009). Internationally trained pharmacists in Great Britain: what do registration data tell us about their recruitment?. Human resources for health, 7, 51. https://doi.org/10.1186/1478-4491-7-51

The Canadian Council for Accreditation of Pharmacy Programmes (CCAPP). (2014). Accreditation Standards for The First Professional Degree In Pharmacy Programmes. Available at https://ccapp.ca/wp-content/uploads/2020/10/2013-2014CCAPP-Annual-Report.pdf

The International English Language Testing System (IELTS). (2019). Test taker performance 2017. Available at: https://www.ielts.org/for-researchers/test-statistics/test-takerperformance

Travel.State.Gov. (2019). Classes of Immigrants Issued Visas at Foreign Service Posts. Available at: https://travel.state.gov/content/dam/visas/Statistics/AnnualReports /FY2018AnnualReport/FY18AnnualReport\%20-\%20Tablell.pdf

United Nations, Department of Economic and Social Affairs, Population Division. (2017). International Migration Report 2017: Highlights (ST/ESA/SER. A/404). Available at:

https://www.un.org/en/development/desa/population/migratio n/publications/migrationreport/docs/MigrationReport2017_Hig hlights.pdf

Vincent, W.R., Steinke, D.T., \& Fink, J.L. (2010). State boards of pharmacy regulation of the supervision of pharmacist interns. American journal of pharmaceutical education, 74(1), 3. https://doi.org/10.5688/aj740103

Wilson, K., Langley, C., Jesson, J., \& Hatfield, K. (2006). Mapping teaching, learning and assessment in the MPharm in UK schools of pharmacy. Pharmaceutical Journal, 277(7419), 369-372 